\title{
A Review on Self Compacting Concrete with Cementitious Materials and Fibers
}

\author{
Noor Ahmed Memon \\ Department of Civil Engineering \\ Quaid-e-Awam University of Engineering, \\ Science \& Technology \\ Nawabshah, Pakistan \\ nahmedmemon@gmail.com
}

\author{
Muneeb Ayoub Memon \\ Department of Civil Engineering \\ Quaid-e-Awam University of \\ Engineering, Science \& Technology \\ Nawabshah, Pakistan \\ engr.muneebmemon@gmail.com
}

\author{
Nawab Ali Lakho \\ Department of Civil Engineering \\ Quaid-e-Awam University of \\ Engineering, Science \& Technology \\ Nawabshah, Pakistan \\ nawablakho@gmail.com
}

\author{
Fareed Ahmed Memon \\ Department of Civil Engineering \\ Mehran University of Engineering \& \\ fareed.memon@faculty.muet.edu.pk
}

\author{
Manthar Ali Keerio \\ Department of Civil Engineering \\ Quaid-e-Awam University of \\ Engineering, Science \& Technology \\ Larkana, Pakistan \\ Mantharali99@quest.edu.pk
}

Ammaar Noor Memon

Department of Civil Engineering

Mehran University of Engineering \&

Technology, Jamshoro, Pakistan

anmemon96@gmail.com

\begin{abstract}
Self-compacted concrete (SCC) is cast in the formwork without compaction and it fulfills the formwork due to its own weight. SCC is considered to have many advantages in comparison with conventional concrete like improved construction quality, faster construction activity, reduced cost etc. SCC is produced with the same ingredients of normal concrete. However, cementitious materials are also adopted to replace the cement content in SCC in order to use waste materials from industries and agricultural products. To further enhance the performance of SCC, different types of fibers are tried in order to produce fiber reinforced SCC. The fibers in the concrete bridge the cracks and diffuse the crack propagation which improves mechanical properties. In developed countries SCC has reasonable acceptance in construction industry but in developing countries like Pakistan has not gained acceptance. This paper is focused on undertaking a review of SCC with cement replacement and fiber reinforcement materials. The main objective of this paper is to compile the literature in order to understand the various properties of SCC in fresh and hardened state when these cement replacement materials and fibers are used.
\end{abstract}

Keywords-self-compacting concrete; cement replacing materials; fiber reinforcement

\section{INTRODUCTION}

Self-compacting concrete (SCC) is a type of concrete which is produced without compacting effort in form work. It settles by its own weight without any bleeding and segregation and behaves cohesive enough [1]. The use of SCC is believed to provide various advantages like reduced construction time, labor cost and noise pollution, ease to fill the congested and thin sections. It also facilitates casting in congested areas of construction. In recent years, different types of filler as a partial cement replacement have been widely used in SCC. With this replacement, SCC can be a more sustainable material [2]. The high flow and resistance to segregation abilities of SCC can be achieved by adding large quantities of super plasticizer and filler materials in it. Though there are many filler materials that have been used in SCC manufacturing, the commonly used fillers are silica fume, fly ash, iron slag etc. [3]. SCC prepared with micro-fillers and mineral admixtures as a partial replacement of cement becomes economical [4]. Normally SCC is produced with smaller water cement ratio which results in high strength, low permeability and more durability when compared to normal concrete produced with compaction with the use of vibrators. These properties of SCC are further improved by the addition of fibers. The fibers work as crackarresters which bridge the cracks and also resist crack propagation. However, the workability of SCC reduces with the addition of fibers and this reduction is dependent upon the type, shape, size and dosage of fibers used [5].

\section{LITERATURE REVIEW}

\section{A. Cementitious Materials}

Literature reports wide use of cementitious materials. The effect of cementitious materials is investigated on various properties of SCC in fresh and hardened state. Authors in [6] investigated the fresh and hardened properties of SCC experimentally by using furnace slag as partial replacement of cement. The $\mathrm{w} / \mathrm{b}$ ratio was kept constant at 0.37 . The slag was used from $0 \%$ to $30 \%$ by cement weight. The effect of slag was investigated in terms of slump flow, shrinkage and compressive strength by UPV. It was observed that the slump flow varies 
with the dosage of slag and it was within the designed value of $550 \mathrm{~mm}$ to $700 \mathrm{~mm}$ when $15 \%$ of slag was used exhibiting maximum compressive strength. The drying shrinkage increased with an increase in slag dosage but SCC with slag had not any sign of bleeding pores and segregation of aggregates. Authors in [7] carried an experimental study to understand the influence of natural zeolite (NZ) on different properties of SCC. NZ was used from 0 to $20 \%$ with an increment of $5 \%$ with different water binding ratios. The results revealed increase in passing ability and viscosity of SCC with the addition of NZ but loss in flow ability with hauling time. Also the increase in NZ dosage caused decrease in slump flow. The compressive and tensile strength of SCC with NZ were found to be dependent upon $\mathrm{w} / \mathrm{b}$ ratio and the enhanced compressive strength was achieved with slump flow more than $550 \mathrm{~mm}$. The UPV values were independent of NZ particularly at high compressive strength. Water absorption of SCC with $\mathrm{NZ}$ was decreased with passage of time.

Authors in [8] used metakaolin (MK) as cement replacement material from ( 0 to $20 \%$ ). Three w/b ratios 0.32 , 0.38 and 0.45 were adopted. The addition of MK resulted in increase in workability and rheological properties of SCC, even without any use of VMA. A remarkable enhancement of the order of $27 \%$ in compressive strength was observed at 14 days. A similar trend was observed in case of tensile strength. It was reported that the compressive strength can be predicted by regression model in terms of UPV. The use of MK reduced water absorption of SCC below 3\%. Overall 10\% MK is proposed as optimum dosage as cement replacement in SCC. Authors in [9] used cement kiln dust (CKD) as partial cement replacement to develop high performance SCC. Cement was replaced by weight $(0 \%, 10 \%, 20 \%$ and $30 \%)$ while keeping other constitutes constant. The results showed that flow ability and mechanical properties decrease with increasing CKD replacement. However, high strength SCC could be produced with 20\% CKD replacement while high performance SCC could be produced with $30 \%$ CKD replacement. CKD in SCC reduces the dynamic modulus of elasticity and increases the damping capacity. Authors in [10] investigated the feasibility of the SCC's medium strength prepared with local filler material (i.e. CKD) theoretically and practically. CKD replacement was $0 \%, 20 \%, 30 \%$ with 0.38 and 0.42 water/binder ratios. Results showed fluidizing effect in the mixtures due to CKD which allows the use of smaller amount of cement with same finer content. The SCC having $35 \mathrm{MPa}$ strength can be produced with $30 \%$ of CKD and 0.42 of water/fines ratio. Authors in [11] reported enhanced workability, compressive strength and flexural strength of SCC with increased dosage of CKD. The optimum CKD dosage is suggested to be $10 \%$ in terms of strength properties.

Authors in [12] used silica fume (SF) in SCC with 10\%, $12.5 \%$ and $15 \%$ replacement. Slump flow, V-funnel, J-Ring, LBox, U-Box tests were conducted in order to measure the fresh properties of SCC. UPV and compressive strength by using rebound hammer were conducted to measure mechanical characteristics of SCC. The results revealed enhanced properties of SCC both in wet and hardened state. Maximum $6 \%$ SF dosage is suggested. Authors in [13] studied the influence of high exposing temperature on the strength properties (compressive and tensile) and durability (porosity, loss of mass and permeability) of SCC. Cement was replaced by fly ash from $0 \%$ to $50 \%$ and exposing temperature was $20^{\circ} \mathrm{C}, 100^{\circ} \mathrm{C}, 200^{\circ} \mathrm{C}$ and $300^{\circ} \mathrm{C}$. It was reported that the tensile strength was significantly reduced due to the increasing of the temperature and fly ash dosage, but compressive strength decreased marginally.

Literature not only reports the use of cementitious materials individually but also the studies conducted with two or more cementitious materials used together. Authors in [14] used silica fume and fly ash as partial replacement of cement from $5 \%$ to $25 \%$ of fly ash with $5 \%$ increment and $2.5 \%$ to $12.5 \%$ of $\mathrm{SF}$ with $2.5 \%$ increment. Silica fume showed increase in fresh and hardened properties. SCC with fly ash exhibited lower compressive strength. Authors in [15] investigated experimentally rheological properties with the addition of silica nano particles, silica fume and fly ash. The results revealed the improvement in rheological properties of SCC with fly ash dosage. The mixture of SF and Nano siliceous particles added together enhanced both mechanical and rheological state. Authors in [16] performed sorptivity test to determine the surface water absorption of the SCC obtained by mixing fly ash and silica fume. Addition of $20 \%$ or more fly ash in SCC resulted in significant reduction of water absorption. A noticeable reduction in sorpitivity is obtained, but in case of binary replacement of silica fume and fly ash the decrease in water absorption is not of such extent as observed in separate replacement. However, compressive strength increase is more significant in case of the addition of both fly ash and silica fume together.

Authors in [17] prepared a mix of SCC blended with microwave incinerated rice husk ash (MIRHA) and 20\% fly ash to investigate the effect of fire flame on it. Fire flame temperatures of $200^{\circ} \mathrm{C}, 400^{\circ} \mathrm{C}, 600^{\circ} \mathrm{C}, 800^{\circ} \mathrm{C}, 1000^{\circ} \mathrm{C}$ and $1200^{\circ} \mathrm{C}$ for 1 hour exposure duration were maintained. The weight and compressive strength of SCC reduced with enhanced flame temperature. Also high temperatures caused improved spalling effect. Authors in [18] investigated the effect of limestone powder (LP) and fly ash (FA) on micro-structural and hydration properties of SCC. They conducted X-ray diffraction, scanning electron microscopy (SEM) and mercury intrusion tests, In addition, image and thermo gravimetric analysis were carried out. The results revealed identical compressive strength in case of LP and FA ranging from 50 to $60 \mathrm{MPa}$ at 28 days. The microstructure of SCC was different with LP and FA with same replacement while SCC with FA was found to be more suitable than SCC with LP. Authors in [19] tested 33 mixes of SCC containing 495 samples with SF and FA. The mixtures contained iron slag as replacement of fine aggregates were produced with superplasticizer $(0.5$ to $1.8 \%$ of cementitious weigh). Compressive strengths at 3,7 , 14, 28 and 56 days were determined. It was found that concrete with $30 \%$ fly ash and $20 \%$ silica fume the exhibited highest compressive strength.

Authors in [20] optimized different compositions of SCC by using "Concrete LabPro2" software followed by an experimental study by casting SCC with waste of marble and tiles as mineral admixture. It was found that the concrete with 
these minerals exhibits satisfactory fluidity and resistance to segregation. UPV compressive strength and spilt tensile strength tests were also carried at 3, 7, 14 and 28 days. These tests reflected the sufficient strength properties suitable to SCC with these admixtures. However, in comparison, the SCC with marble waste exhibited lower strength than the SCC with lime stone.

Authors in [21] produced SCC with high content of waste perlite powder (WPP), slag (blast furnace) and MK. The results identified a pronounced pozzolanic effect of WPP on concrete microstructure. This effect caused enhancement in compressive strength and durability performance of SCC. Authors in [22] used three mineral admixtures namely $\mathrm{SF}(5 \%$ to $25 \%$, increment $5 \%$ ), MK ( $5 \%$ to $20 \%$, increment $5 \%$ ) and GGBFS ( $25 \%$ to $100 \%$, increment $25 \%$ ). The results were compared with normal concrete of $60 \mathrm{MPa}$. Water-binder ratio was obtained as 0.4 with optimum dosages of SP and VMA as $2.3 \%$ and $0.15 \%$ weight of cement respectively. It was reported that $50 \%$ GGBFS, $10 \%$ SF and $20 \%$ MK were found to be the optimum values as partial substitute to cement. Authors in carried out tests to improve the properties of low cement SCC (with 50\% OPC and 50\% GGBFS and low calcium fly ash) by using dolomite powder (DP). They concluded that DP had not showed any effect on the setting properties of SCC blended with slag and OPC. However, significant effect was observed on the properties of SCC blended with ternary mixture (i.e. Slag, OPC \& FA). Furthermore, a significant enhancement in flow ability and compressive strength was observed with DP adjustment in ternary blended mixes of SCC. The maximum 7 days compressive strength of hardened mortars was achieved with addition of $30 \%$ (by weight) of DP. However, $50 \%$ dosage of DP provided satisfying properties required in concrete structures. Authors in [24] focused on the durability of SCC incorporating copper slag (CS) as fine aggregates and $\mathrm{MK}$ as substitute to FA. A total of seven concrete mixes with constant percentage of $60 \%$ OPC and remaining $40 \%$ adjusted between combined replacement of FA and MK CS was used from 0 to $100 \%$. Results revealed that fresh properties declined with inclusion of MK although escalated with increment of CS content. All SCC mixes exhibited higher compressive and splitting tensile strength than control concrete. The minimum carbonation depth was marked for $100 \%$ CS substitution with $10 \% \mathrm{MK}$ as replacement to FA. The maximum electrical resistivity and resistance to sulfate attack were obtained for $20 \%$ CS substitution while UPV values of all the mixes were under the excellent quality of concrete beyond 7 days of curing. On full replacement of sand by CS with $10 \% \mathrm{MK}$, initial surface absorption and sorptivity were significantly lower than control concrete at each curing period. This study suggested that CS together with MK can be a potential substitute to natural sand in the construction sector to overcome the scarcity of aggregates.

Author in [25] studied the effects of ternary system on corrosion behavior of SCC which is formed using MK and selfcombusted ash of rice husk (SCRHA). To achieve the objective, ordinary Portland cement (OPC) was replaced by SCRHA while preparing different mixes. In binary system, the replacement was from 0 to $30 \%$ (with $5 \%$ increment). On the hand, for ternary the replacement was done from 0 to $40 \%$ (with 5\% increment). The experimental results revealed that SCC with the replacement of $15 \%$ SCRHA, $10 \% \mathrm{MK}$ and $10 \% \mathrm{SCRHA}+10 \% \mathrm{MK}$ was found to be optimum dosage to achieve satisfactory performance for all the parameters investigated. Authors in [26] investigated the fresh and mechanical properties of SCC containing an agro-waste byproduct "Palm oil fuel ash" (POFA) as partial cement replacement. In this study, a new method was introduced to prepare treated POFA, called modified treated POFA (MTPOFA) with full usage of original POFA. It was then used as a cement replacement at $0 \%, 30 \%, 50 \%$, and $70 \%$ to produce sustainable SCC. Test results showed that the fresh properties of all concretes containing MT-POFA were ranged within SCC requirements. The mechanical properties exhibited a reduction at the early ages of MT-POFA concretes. However, with increased curing time, these properties were significantly improved. SCC incorporating MT-POFA performed better than control SCC in terms of rapid chloride permeability test and elevated temperature. In general, MT-POFA was proposed to be cement replacement in SCC. Authors in [27] investigated the engineering properties of SCC with magnetic water and SF, $\mathrm{MK}$, rice husk ash and FA. Results indicated that magnetic water and pozzolanic materials in SCC can improve the selfcompatibility criterion in terms of flow-ability and viscosity. Furthermore, SCC mixture containing magnetic water and $20 \%$ of SF can be considered as an optimum mix design at the age of 28 days. Compressive strength and splitting tensile strength increased up to $49 \%$ and $41 \%$, respectively and the value of water absorption decreased by 55\%. Moreover, magnetic water can reduce the amount of high range water reducer (HRWR) required for SCC up to $45 \%$.

\section{B. Fiber Reinforcement}

Authors in [28] tested five concrete mixes of steel fiber reinforced high strength lightweight self-compacting concrete (SHLSCC). Steel fibers were added from $0 \%$ to $1.25 \%$. A remarkable influence of steel fibers is identified due to fiber dosage being $1 \%$ and beyond. The compressive and flexural strength increased by $37 \%$ and $110 \%$ respectively. The modulus of elasticity was independent of fiber effect. Authors in [29] focused on the performance of self-compacting lightweight concrete (SCLC) having fibers of steel. Two types of SCLC, one with coarse aggregates only and another with coarse and fine lightweight aggregates were cast and tested. Steel fibers $(0.5 \%$ volume fraction $)$ were added. The slump flow of fiber SCLC mixes was found within $600-700 \mathrm{~mm}$ without segregation. All the mixes yielded compressive strength above $30 \mathrm{MPa}$ and density within $1700-1900 \mathrm{~kg} / \mathrm{m}^{3}$ at 28 days. Tensile and bending strength increased due to fibers and all the mixes exhibited sufficient thermal insulation in comparison to the normal concrete. The autogenous and drying shrinkage were around 150 micro strains. Authors in [1] compared the properties of SCC having steel fibers and class F FA with plain normal compacted concrete (NCC). Overall ten SCC and one NCC mixes with constant dosage of cementitious material $(35 \%)$ and $0.31 \% \mathrm{w} / \mathrm{b}$ ratio were cast. The effect of different aspect ratio and volumetric fraction of steel fibers on strength properties of SCC and NCC were studied. It was observed that the ductility of concrete increased significantly due to the addition of fibers but a marginal increase in the 
ultimate strength properties was obtained. Authors proposed $1 \%$ as volumetric fraction and 25 as aspect ratio of fibers for adequate performance of SCC in terms of strength.

Authors in [30] investigated the compressive, tensile and flexural strength properties of SCC manufactured with recycled steel fibers and silica fume. Results revealed enhancement in strength properties and impact resistance of SCC due to the availability of SF. Authors carried a regression analysis which showed a considerable correlation between strength properties and impact resistance. Authors in [31] investigated the fresh and hardened properties of self-compacting concrete containing hybrid steel fibers. In this study straight and corrugated steel fibers with different lengths $(6 \mathrm{~mm}$ and $35 \mathrm{~mm})$ and crosssections with volume ratio $1.0 \%$ to $3.0 \%$ were used to ensure the compressive strength and flexural behavior of SCC. It was found that the hybrid fiber did not influence the workability but pronouncedly decreased the passing ability. Based on the mechanical properties, the results showed flexural parameters of HFR-SCC enhanced with hybrid fiber addition and at low dosage rates $(\leq 2 \%)$. However, using higher amount of fibers did not cause further increase in flexural parameters. Authors in [5] tried fibrillated polypropylene fibers and straight steel fibers with different aspect ratios and volumetric friction to produce fiber reinforced self-compacting concrete (FRSCC). They reported that SCC of sufficient self-compacting properties may be produced with fibers. It was also indicated that the fiber type and mix composition had significantly affected the flow properties of FRSCC. Authors in [32] studied SCC containing hybrid fibers (steel and polypropylene (PP) fibers). Steel fibers were used with three different volume ratios $(0.5 \%, 1.0 \%$, and $1.5 \%)$ with two amounts $(0.3 \%, 0.9 \%)$ of two types of polypropylene fibers. It was found that volume ratio higher than $1.4 \%$ does not satisfy the passing ability requirements for SCC. The mixes containing $0.9 \%$ of $38 \mathrm{~mm}$ PP may be used in conventional concrete. Enhancement in flexural and tensile strength and toughness with increase of steel fibers volume ratio were observed, while PP fibers reduced the flexural and tensile strength but on other hand caused a beneficial effect on toughness of (HFR-SCC).

Author in [33] studied the effect of glass fiber and fly ash on SCC of M20 and M30 grade. Workability and strength properties were studied with $25 \%$ fly ash and 0.05 to $0.2 \%$ of GF (with $0.05 \%$ increment) by mix volume. Results showed that the compressive strength increased up to $0.15 \%$ of fiber while adequate increase in flexural strength is obtained with $0.1 \%$ of glass fibers. Authors in [34] used waste plastic fibers (WPF) by cutting beverage bottles in SCC mixtures produced with $0.35 \mathrm{w} / \mathrm{b}$ ratio and fly ash. WPF from 0 to $2 \%$ by volume with an increment of $0.25 \%$ was used. Fly ash was used as replacement at $25 \%$ cement weight. Workability of SCC along with compressive and flexural strength was studied at 7,14 and 28 days. The addition of WPF showed adverse effect on workability while the compressive and flexural strength increased. Authors in [35] investigated the effect of inclusion of different steel and polymer fibers on the fresh properties of SCC. For this purpose various commercial and widely available types of steel and polymer fibers were used. The volume of steel fibers ranged from $0 \%$ to $1.5 \%$ and polymer fibers ranged from $0 \%$ to $0.9 \%$. It was concluded that L-box test provides useful information of filling and passing ability of fiber-reinforced SCC. In addition, lesser segregation resistance of the SCC was achieved. Authors in [36] determined the bond strength between old concrete and new SCC. They used latex and fibers to achieve the study objectives. The factors affecting slant shear bond strength between old concrete and new SCC were discussed. Slant shear test was carried out. They concluded that the inclusion of latex (5\% and 10\%) and PP fiber exhibited enhanced slant shear bond strength between old concrete and new SCC. It was proposed that prism specimen may be considered more reliable than cylinder specimen to assess slant shear strength. Authors in [37] studied the shrinkage and durability properties of SCC incorporating granite sawing waste (GSW) and PP fibers along with fly ash. Shrinkage and durability properties; water absorption, porosity, acid resistance, sulfate resistance and chloride penetration were studied. Reduced SCC shrinkage was observed when using GSW and PP fibers, while, resistance against acid attack, chloride penetration and sulfate was improved. Reduction in water absorption was observed at $10 \%$ of GSW. Authors in [38] studied the suitability of river gravel as substitute of crushed aggregate to produce high strength steel fiber-river gravel-self compacting concrete (SFRGSCC). The results exhibited improved rheology, enhanced concrete flowing, reduced yield stress and entrapped air. SCC became more fragile under compression, tension and bending due to less strain capacity. SCC ductility improved with steel fibers $(0.75 \%$ and $1 \%$ fiber dosage), moreover, the reinforcement significantly increases the RGSCC toughness which was even more significant under direct tension and bending loads.

\section{Replacement of Fine Aggregates}

Conventionally the waste materials obtained from various resources are added in SCC as partially cement replacement. However, their effect depend upon various factors particularly fineness and reactivity characteristics in presence of cement and water. Thus, a trend is also observed to use these materials as fine aggregates in SCC, such as, coal bottom ash [39], copper slag [40], plastic waste [41] and GGBFS [42 ]etc. Since this paper is focused to review the use of these wastes as cement replacement materials, the detailed review about these materials used as fine aggregate replacement in SCC is beyond the scope of paper.

\section{CONCLUSIONS}

Based on the literature review conducted and highlighted in this paper it may be concluded that;

- A wide variety of waste materials is used as cement replacement in SCC.

- Most studies are carried out in order to investigate the effect of these materials on fresh properties (flow ability, passing ability and segregation resistance) and mechanical properties (compressive, tensile and flexural strength). In addition, durability characteristics also have been one of the studied parameters.

- The fresh properties are significantly affected by the addition of cementitious materials. However, the effect 
depends upon the type, dosage and combination of adopted cementitious materials.

- Mechanical properties were also remarkably affected by the cementitious materials used. The effect is significant on certain types of waste materials such as silica fume and fly ash.

- Different fibers added as fiber reinforcement in SCC were used.

- Fibers exhibit pronounced effect on both fresh and hardened properties of SCC.

- In most of the cases the fresh properties of concrete (flow ability, passing ability and segregation resistance etc) decrease with the addition of fibers but the mechanical properties increased significantly particularly when the specimen are tested in tension and bending. Type and shape of fiber, aspect ratio and volumetric fraction are observed to be major factors governing the performance of SCC.

- The waste materials obtained from different resources are also used as replacement of fine aggregates but the discussion in this regard is beyond the scope of this paper.

Further, in Pakistan the use of SCC is not common particularly with the applications of cementitious materials and fiber reinforcement. This is because the properties of SCC vary due to variations in dosage, type, compination and application of cementitious materials and fiber reinforcement. Nonetheless, the local resources from where these materials are obtained is also another major issue to consider because the properties of cementitious materials depend upon the way these materials are generated as byproducts from the local industry, agricultural land or naturally available mineral sources. The availability of cementitious materials varies with the locality, e.g. sorah [43] is one of the promising cementitious materials locally available in Pakistan which may be tried in SCC. Thus, it may be concluded that there is always need of understanding the behavior of SCC with materials and fibers obtained from local resources.

\section{ACKNOWLEGMENT}

Authors are grateful to the Quaid-e-Awam University of Engineering, Science and Technology, Nawabshah, Pakistan for providing the research facilities.

\section{REFERENCES}

[1] B. K. Rao, V. Ravindra, "Steel Fiber Reinforced Selfcompacting Concrete Incorporating Class F Fly Ash", International Journal of Engineering Science and Technology, Vol. 2, No. 9, pp. 4936-4943, 2010

[2] L. Coppola, T. Cerulli, D. Salvioni, "Sustainable development and durability of self-compacting concretes", 8th CANMET/ACI International Conference on Fly Ash, Silica Fume, Slag and Natural Pozzolans in Concrete, pp. 29-50, 2004

[3] P. Aggarwal, R. Siddique, Y. Aggarwal, S. M. Gupta, "Self-compacting concrete-procedure for mix design", Leonardo Electronic Journal of Practices and Technologies, Vol. 7, No. 12, pp. 15-24, 2008

[4] M. Nehdi, M. Pardhan, S. Koshowski, "Durability of self-compacting concrete incorporating high-volume replacement composite cements", Cement Concrete Research, Vol. 34, No. 11, pp. 2103-2112, 2004
[5] A. S. El-Dieb, M. M. Reda Taha, "Flow characteristics and acceptance criteria of fiber-reinforced self-compacted concrete (FR-SCC)", Construction and Building Materials, Vol. 27, pp. 585-596, 2012

[6] H. Y. Wang, C. C. Lin, "A study of fresh and engineering properties of self-compacting high slag concrete (SCHSC)", Construction and Building Materials, Vol. 42, pp. 132-136, 2013

[7] M. M. Ranjbar, R. Madandoust, S. Y. Mousavi, S. Yosefi, "Effects of natural zeolite on the fresh and hardened properties of self-compacted concrete", Construction and Building Materials, Vol. 47, pp. 806-813, 2013

[8] R. Madandoust, S. Y. Mousavi, "Fresh and hardened properties of selfcompacting concrete containing metakaolin", Construction and Building Materials, Vol. 35, pp. 752-760, 2012

[9] K. B. Najim, I. Al-Jumaily, A. M. Atea, "Characterization of sustainable high performance/self-compacting concrete produced using CKD as a cement replacement material", Construction and Building Materials, Vol. 103, pp. 123-129, 2016

[10] I. R. Viacava, A. A. de Cea, G. R. de Sensale, "Self-compacting concrete of medium characteristic strength", Construction and Building Materials, Vol. 30, pp. 776-782, 2012

[11] M. B. Vanjare, S. H. Mahure, "Experimental Investigation On Self Compacting Concrete Using Cement Kiln Dust", International Journal of Engineering Research \& Technology, Vol. 2, No. 1, pp. 1488-1492, 2013

[12] K. S. Shobana, R. Gobinath, V. Ramachandran, B. Sundarapandi, P. Karuthapandi, S. Jeeva, A. Dhinesh, R. Manoj Kumar, M. Subramanian, "Preliminary study of Self Compacting Concrete by adding Silica FumeA review paper", International Journal of Engineering Research \& Technology, Vol. 2, No. 11, pp. 1293-1304, 2013

[13] N. Phathak, R. Siddique, "Properties of self-compacting concrete containing fly ash subjected to elevated temperatures", Construction and Building Materials, Vol. 30, pp. 274-280, 2012

[14] A. Dinesh, S. Harini, J. P. Jeba, J. Jincy, J. Shagufta, "Experimental study on self compacting concrete", International Journal of Engineering Sciences \& Research Technology, Vol. 6, No. 3, pp. 42-50, 2017

[15] M. Jalal, A. Pouladkhan, O. F. Harandi, D. Jafari, "Comparative study on effects of Class F fly ash, nano silica and silica fume on properties of high performance self compacting concrete", Construction and Building Materials, Vol. 94, pp. 90-104, 2015

[16] H. Y. Leung, J. Kim, A. Nadeem, J. Jaganathan, M. P. Anwar, "Sorptivity of self-compacting concrete containing fly ash and silica fume", Construction and Building Materials, Vol. 113, pp. 369-375, 2016

[17] M. F. Nuruddin, N. M. Azmee, C. K. Yung, "Effect of fire flame exposure on ductile self-compacting concrete (DSCC) blended with MIRHA and fly ash", Construction and Building Materials, Vol. 50, pp. 388-393, 2014

[18] M. K. Mohammed, A. R. Dawson, N. H. Thom, "Production, microstructure and hydration of sustainable self-compacting concrete with different types of filler", Construction and Building Materials, Vol. 49, pp. 84-92, 2013

[19] D. Raharjo, A. Subakti, Tavio, "Mixed Concrete Optimization Using Fly Ash, Silica Fume and Iron Slag on the SCC's Compressive Strength", Procedia Engineering, Vol. 54, pp. 827-839, 2013

[20] M. Tennich, A. Kallel, M. B. Ouezdou, "Incorporation of fillers from marble and tile wastes in the composition of self-compacting concretes", Construction and Building Materials, Vol. 91, pp. 65-70, 2015

[21] A. El Mir, S. G. Nehme, "Utilization of industrial waste perlite powder in self-compacting Concrete", Journal of Cleaner Production, Vol. 156, pp. 507-517, 2017

[22] S. S. Vivek, G. Dhinakaran, "Fresh and hardened properties of binary blend high strength self compacting concrete", Engineering Science and Technology, an International Journal, Vol. 20, pp. 1173-1179, 2017

[23] H. A. Nguyen, T. P. Chang, J. Y. Shih, H. S. Djayaprabha, "Enhancement of low-cement self-compacting concrete with dolomite Powder", Construction and Building Materials, Vol. 161, pp. 539-546, 2018 
[24] R. Sharma, R. A. Khan, "Influence of Copper Slag and Metakaolin on the Durability of Self Compacting Concrete", Journal of Cleaner Production, Vol. 171, pp. 1171-1186, 2018

[25] V. Kannan, "Strength and durability performance of self compacting concrete containing self-combusted rice husk ash and metakaolin", Construction and Building Materials, Vol. 160, pp. 169-179, 2018

[26] B. Alsubari, P. Shafigh, Z. Ibrahim, M. F. Alnahhal, M. Z. Jumaat, "Properties of eco-friendly self-compacting concrete containing modified treated palm oil fuel ash", Construction and Building Materials, Vol. 158, pp. 742-754, 2018

[27] M. Gholhaki, A. kheyroddin, M. Hajforoush, M. Kazemi, "An investigation on the fresh and hardened properties of self-compacting concrete incorporating magnetic water with various pozzolanic materials", Construction and Building Materials, Vol. 158, pp. 173-180, 2018

[28] S. Iqbal, A. Ali, K. Holschemacher, T. A. Bier, "Mechanical properties of steel fiber reinforced high strength lightweight self-compacting concrete (SHLSCC)", Construction and Building Materials, Vol. 98, pp. $325-333,2015$

[29] T. M. Grabois, G. C. Cordeiro, R. D. Toledo Filho, "Fresh and hardened-state properties of self-compacting lightweight concrete reinforced with steel fibers", Construction and Building Materials, Vol. 104, pp. 284-292, 2016

[30] M. Mastali, A. Dalvand, "Use of silica fume and recycled steel fibers in self-compacting concrete (SCC)", Construction and Building Materials, Vol. 125, pp. 196-209, 2016

[31] M. Pajka, T. Ponikiewski, "Experimental investigation on hybrid steel fibers reinforced self-compacting concrete under flexure", Procedia Engineering, Vol. 193, pp. 218-225, 2017

[32] M. Pajak, "Investigation on Flexural Properties of Hybrid Fibre ReinforcedSelf-Compacting Concrete”, Procedia Engineering, Vol. 161, pp. 121-126, 2016

[33] P. T. S. Sheril "Self Compacting Concrete Using Fly Ash and Glass Fibre", International Journal of Engineering Research \&Technology, Vol. 2, No. 9, pp. 374-376, 2013

[34] A. I. Al-Hadithi, N. N. Hilal, "The possibility of enhancing some properties of self-compacting concrete by adding waste plastic fibers", Journal of Building Engineering, Vol. 8, pp. 20-28, 2016

[35] T. Ponikiewski, J. Katzer, "Properties of fresh SCC mix reinforced by different types of steel and polymer fibre", Construction and Building Materials, Vol. 62, pp. 96-101, 2014

[36] A. M. Diab, A. E. M. A. Elmoaty, M. R. Tag Eldin, "Slant shear bond strength between self compacting concrete and old Concrete", Construction and Building Materials, Vol. 130, pp. 73-82, 2016

[37] K. Aarthi, K. Arunachalam, "Durability Studies on Fibre Reinforced Self Compacting Concrete with Sustainable Wastes", Journal of Cleaner Production, Vol. 174, pp. 247-255, 2017

[38] M. A. da Silva, M. Pepe, R. G. M. de Andrade, M. S. Pfeil, R. D. T. Filho, "Rheological and mechanical behavior of High Strength Steel Fiber-River Gravel Self Compacting Concrete", Construction and Building Materials, Vol. 150, pp. 606-618, 2017

[39] R. Siddique, "Compressive strength, water absorption, sorptivity, abrasion resistance and permeability of self-compacting concrete containing coal bottom ash", Construction and Building Materials, Vol. 47, pp. 1444-1450, 2013

[40] R. Sharma, R. A. Khan, "Durability assessment of self compacting concrete incorporating copper slag as fine aggregates", Construction and Building Materials, Vol. 155, pp. 617-629, 2017

[41] S. M. Hama, N. N. Hilal, "Fresh properties of self-compacting concrete with plastic waste as partial replacement of sand", International Journal of Sustainable Built Environment, Vol. 6, No. 2, pp. 299-308, 2017

[42] H. L. Muttashar, M. A. M. Ariffin, M. N. Hussein, M. W. Hussin, S. Bin Ishaq, "Self-Compacting Geopolymer Concrete With Spend Garnet As Sand Replacement", Journal of Building Engineering, Vol. 15, pp. 8594, 2018

[43] A. Saand, M. A. Keerio, D. K. Bangwar, "Effect of Soorh Metakaolin on Concrete Compressive Strength and Durability", Engineering
Technology \& Applied Science Research, Vol. 7, No. 6, pp. 2210-2214, 2017 